The digestibility study (trial $A$ ) was made on 20 castrated male pigs (5 groups) placed in individual pens with total collection of the excreta for 10 consecutive days. The energy value of 2 types of cassava was assessed by the substitution method using diets including 25 or 50 p. 100 cassava $(1$ or 2$)$ in the place of a diet containing maize-soybean meal (control group). The digestible energy values of cassava 1 and 2 were 3640 and $3930 \mathrm{Kcal}$ (per $\mathrm{kg}$ D.M.), respectively, corresponding to apparent energy digestibility coefficients of 92.4 and 97 p. 100.

In trial $B 80$ fattening pigs were used to compare four diets : the control diet maizesoybean meal (group 1), a diet with 15 p. 100 cassava 1 (group 2), a diet with 30 p. 100 cassava 1 (group 3), a diet with 30 p. 100 cassava 2 (group 4). All of them exhibited the same lysine/digestible energy ratio and the different energy supply according to sex was similar in each group. During the whole fattening period $(23$ to $103 \mathrm{~kg}$ ) the performance of castrated males (daily weight gain, feed conversion ratio) did not change according to the diet $(702 \mathrm{~g}, 3.04 \mathrm{on}$ an average). For the females, contrary to the excellent results obtained with the control group $(805 \mathrm{~g}-2.77)$, addition of cassava (1 or 2) led to a significant decrease in the performance (about 5 p. 100) : $749 \mathrm{~g}-2.98$ (group 2), $759 \mathrm{~g}-2.91$ (group 3), $777 \mathrm{~g}-2.90$ (group 4). The carcass quality was the same in all groups.

In trial $C$ concerning 72 fattening pigs the experimental conditions were strictly identical to those of trial B, but only three diets were compared : a control diet maizesoybean (group 1), a diet with 30 p. 100 cassava 1 (group 2), a diet with 30 p. 100 cassava 2 (group 3). Over the whole period, they all led to comparable results : $682 \mathrm{~g}$ 3.34 (group 1), $696 \mathrm{~g}-3.25$ (group 2), $697 \mathrm{~g}-3.28$ (group 3). Addition of $30 \mathrm{p} .100$ cassava to the diets did not affect the carcass and meat quality.

In trial $D, 384$ piglets were used between 8.6 and $27.7 \mathrm{~kg}$ live weight to compare 4 diets : a control diet maize-soybean meal (group 1) a diet with 10 p. 100 cassava 1 (group 2), a diet with 20 p. 100 cassava 1 (group 3), a diet with 20 p. 100 cassava 2 (group 4). Diets including cassava were rebalanced with nitrogen by means of soybean meal and D.L. methionine. There was no significant difference in the feed intake $(984 \mathrm{~g} / \mathrm{d})$, the weight gain $(544 \mathrm{~g} / \mathrm{d})$ and the feed conversion ratio (1.81) according to diet.

These trials showed the possibilities of replacing maize by cassava of satisfactory quality (cassava 1) or of excellent quality (cassava 2) at the level of $20 \mathrm{p} .100$ in the 2nd age piglet diet and until 30 p. 100 in growing pig diets provided that these diets are rebalanced with nitrogen.

They also showed the variability in the energy value of cassava (trial A), the possible amino acid imbalances, when replacing a large proportion of more protein rich cereals by cassava (trial B). However, it is not possible to draw conclusions on the real effects of fungical and bacterial contaminations (cassava 1) on health and overall performance.

\title{
Influence of the fineness of ground barley on the performance of growing pig
}

\author{
Martine CHAMP et J. DELORT-LAVAL \\ I.N.R.A., Laboratoire de Technologie des Aliments des Animaux, \\ Chemin de la Géraudière, $F 44072$ Nantes Cedex
}

Fine grinding of barley currently practised in pig feeding is compared to some other more energy sparing processes.

These processes include not only a coarse grinding but also a sieving for recycling the largest particles.

Growth and nitrogen balance trials made on 35 to $70 \mathrm{~kg}$ pigs fed a ground barley diet $(97 \mathrm{p} .100)$ showed that : 
- a coarse grinding with recycling of the largest particles on the hammer-mill only led to a very small decrease in the digestibility of the main components of the diet. It had a slightly favourable effect on nitrogen retention as compared with fine grinding. This latter treatment caused gastric abnormalities (parakeratosis and ulcers) in the pigs;

- a distribution of the coarsest meal in our assay into two more homogenous fractions, «fine» and «coarse», was not of any special interest for pig feeding.

\title{
Combined utilization of maize and peas in bacon pig feeding: Influence of the incorporation level, the physical form and the variety
}

\author{
J. CASTAING * et M. LEUILLET ** \\ * Association Générale des Producteurs de Maïs, \\ 1, place Samuel-de-Lestapis, F 64000 Pau \\ **: Institut Technique des Céréales et des Fourrages, \\ 8, avenue du Président-Wilson, F 75116 Paris
}

The experiments made in France the last few years to determine the utilization conditions of protein-rich peas in bacon pig feeding (PEREZ, LEUILLET, BOURDON, 1979) led to recommend a level of incorporation of 15 p. 100 . However, with the variety «Frimas 》 and with feeds in the form of meal, it was shown that peas could be associated with maize at a higher level without changing the pig performance. To carry on this work we made three trials including 272 pigs subjected to individual controls :

In the first trial winter peas «Frimas» were incorporated into the diet at the level of $0,12,24$ and 36 p. 100 . It was confirmed that peas could be associated with maize up to the high level of 24 p. 100 without affecting the performance. At the level of $36 \mathrm{p} .100$ the deterioration of growth and feed efficiency reached 5 p. 100 over the whole fattening period; this effect was more marked in the growing than in the finishing period.

In the second trial where peas of the variety «Frimas» were incorporated into the diet at the level of 0 or $36 \mathrm{p}$. 100, the pelleting of the peas did not reduce the decrease in the performance while it improved by 6 p. 100 the results of the control feed.

The third trial pointed out the large differences between varieties in favour of the spring variety. Utilization of the latter allowed to replace $60 \mathrm{p}$. 100 of the supplementary soybean meal in a diet based on maize without modifying the results.

The lower efficiency of the feed including a high level of «Frimas» did not seem to be due to the tryptophan content of the diets concerned. The minimum content of 0.15 p. 100 of this amino acid generally considered as sufficient was always maintained in the feed substitutes.

However, let us mention the two to three times higher contents of antitrypsin factors in the "Frimas» group as compared to the spring varieties. A better knowledge of these factors and of their causes of variation might allow to determine the present limits of utilization of the protein rich peas in association with maize in bacon pig feeding. 